\title{
E-law Protection: for both Buyers and Sellers
}

\author{
Hameed Ullah Khan ${ }^{1}$ \\ ${ }^{1}$ Department of Information Systems, College of Computer \& Information Sciences, King Saud University, \\ Riyadh, Kingdom of Saudi Arabia \\ Correspondence: Hameed Ullah Khan, Department of Information Systems, College of Computer \& Information \\ Sciences, King Saud University, Riyadh 11543, Kingdom of Saudi Arabia. Tel: 966-1-469-5234. E-mail: \\ hukhanafridi57@yahoo.com or hkhan@ksu.edu.sa
}

\author{
Received: April 13, 2012 Accepted: May 8, 2012 Online Published: May 24, 2012 \\ doi:10.5539/jms.v2n2p90 ＵRL: http://dx.doi.org/10.5539/jms.v2n2p90
}

\begin{abstract}
Law was brought into practice since the inception of humankind on the planet. The importance of law in human life is unquestioned. Civilization operates under commandments, from inception to demise and its implementation is mandatory for constraint of human behaviors in various different situations. Since transgressions to law can vary in there occurrence, crimes committed on-line are of no exception, and therefore constitutes a need for regulation, required to make on-line transactions efficient and without disturbance. In reality, online lawful transactions, under law, are arduous due to difference in locations and accordingly in legal litigations. In such circumstances, friction arises due to in-existing suitable systems in such circumstances. But with the induction of e-laws can yield better results for consumer-vendor protection and also for on-line transactions, it will yield better results.
\end{abstract}

Keywords: disturbed systems, software agents, database management

\section{Introduction}

Business is the mainstay of a country's retinue and as such depends on a demand and supply sequence, the higher the demand more the supply and vice versa. Business is conducted in variety of ways, such as, on-line, off-line, private, corporate, etc. The tariffs for business are monitored under law for both cost and quality control. Saying as such, businesses operate under certain conventions and those transgressing be penalized by edict (McNamara, 2012).

The statistics demonstrates that the rate of crime increases every day in all sectors with business being no exception. This unrest amounts to coerce the judiciary and, regulation is thus brought into effect. Infringement committed during business transactions in cyberspace requires suitable and effective anti-intrusion protocols (Laurie \& Bohm, 2003).

Constitution is the supreme legislation for any country to regulate their undertakings. These are however, made on the local scale, whereby limiting their effectiveness on an international level (Eiselen, 2011).

Trust is developed when there is understanding among the consumers and vendors. It therefore comes down to the fact that as more and more novel innovations and inventions come to light, so will new methods of criminality, and in order to combat this infringement new policies and edicts will be required (Salzman \& Sookman, 2011).

Attack on the data is crime which is illegal attempt. There are two types of attack; nontechnical attack: an attack that uses source to trap people into revealing sensitive information or performing actions that compromise the security of a network. Secondly, technical attack: an attack perpetrated using software and systems knowledge or expertise to reach to the target data as an unauthorized user (Laudon \& Traver 2011).

The rest of the paper is organized as follows. Section 2 presents the background study in detail. In section 3, the proposed system is presented. Methodology and discussion is given in section 4. E-law model is presented in section 5 and finally, conclusion in section 6 .

\section{Background Study}

As e-business (EB) has global implementation, therefore to provide full proof of security, fraud less transactions, cultural consideration, etc., is not yet possible. This needs proper developments on the legal litigations, consumer education, trust \& risk protection, etc. In addition, there is constitutes the need for systems to be developed in 
which both the consumers and vendors interests are sheltered. When discussing business transactions, we come across three types of interactions: first; Laymen interacting with Business men, second; Laymen interacting with Laymen and finally; Business men interacting with Business men. The chances or probability for compatible business takes place on the basis of how much one group is familiar with the perks of the trade and how one group is able to overcome another group. Besides, the model of consumer behavior online depends on certain variables for decision making, such as, independent variables, intervening variables, dependent variables and decision-making variables (Manitoba Laws, 2012).

The concern of the United Nations (UN) is also growing on the fields of cyber business. Therefore, the United Nations Commission on International Trade Law (UNCITRAL) must expound a model legislation that would serve as a foundation/ stepping stone for states in order to update their legislation regarding cyber business interactions. The commission will also bring awareness of the likelihood that the model law would be used in a number of states with limited familiarity with the type of communication techniques considered in the model law (United Nation, 1999).

Many countries they are well developed capitalist countries, and are well developed in computer industry. While where computer crime is also very serious and has formulated a more comprehensive terms of the punishment related to computer crime laws, which is related to prevent and control computer crimes. There is a very important inspiration and reference to other countries to adopt the same to stop computer crimes (Wang, 2011).

The implementations of laws are based on certain criterion, such as, the code of criminal procedure. The code of criminal procedure identifies the authorities in power and the Chief-Justice of the Supreme Civil Appellate Court, the Judge of the High Civil Court, the judge are responsible for executing sentences and public prosecutors. All of these judicial officers have the right to ensure that there are no wrongfully detained persons (Mahmoud \& Nigel, 2011).

Internet based law means the open and decentralized global network connections of networks of computers and similar devices to each other for the electronic exchange of information using standardized communication protocols. This applies to retailer sale or e-tailor agreements formed by Internet communications. The Consumer is entitled to make void the transaction if not provided adequate information by the vendor. All laws from 129(2) to 135 are applicable under the agreement. For more details see References (Manitoba, 2011; Moira, 2011).

Accordingly to cybercrime; indeed is a clear and present current danger to online business ventures, and a stern legislation is required to curb the menace. A labeling approach to the definition of crime argues that; crime only really exists when there has been a social response to particular activity that labels that activity as criminal. If there is no label, there is in effect no crime. A human rights approach says that; crime occurs whenever a human right has been violated, regardless of the legality or otherwise in the action. Such a conception also expands the definition of crime to include oppressive practices such as racism, sexism, and class-based exploitation. A human diversity approach defines; crime in terms of the manner in which deviance represents a normal response to oppressive or unequal circumstances. A major focus here is on power relations, and the attempts by dominant groups to restrict human diversity of experience, language, and culture. The variation in definition often has real consequences upon how different types of behavior are dealt with at a practical level (White \& Haines, 2005).

\section{Proposed System}

Business connotes growth, employment and prosperity. Business interactions should therefore be shielded and secured with transactions managed by decree that different echelons of dishonesty and deceit can be impeded. The importance of e-business life cycle is illustrated in the Figure 1.

\subsection{Discussion on Figure 1}

Every e-business having a starting day and finishing day but it has the laws to manage at every stage. E-businesses start at certain proper time with complete feasibility information. In the second stage the schedule is developed to give proper shape to handle its operations. The implementation and managing stages last for the entire life cycle till its finishing day of completion. During all operations it must work under the control of e-laws. The implementation of e-laws provide them protections, such as: Authentication: The process by which one entity verifies another entity, Authorization: Restriction to ensures that a person has the right to access certain resources, Auditing: Record keeping by collecting information about attempts to access particular resources, use particular privileges, or perform other security actions, Confidentiality: Security of data by keeping private or sensitive information from being disclosed to unauthorized individuals, entities, or processes, Integrity: To protect Data changes ability from being altered or destroyed in an unauthorized or accidental manner, Nonrepudiation: The ability to stop buyer and sellers from refusing to own his signature. 


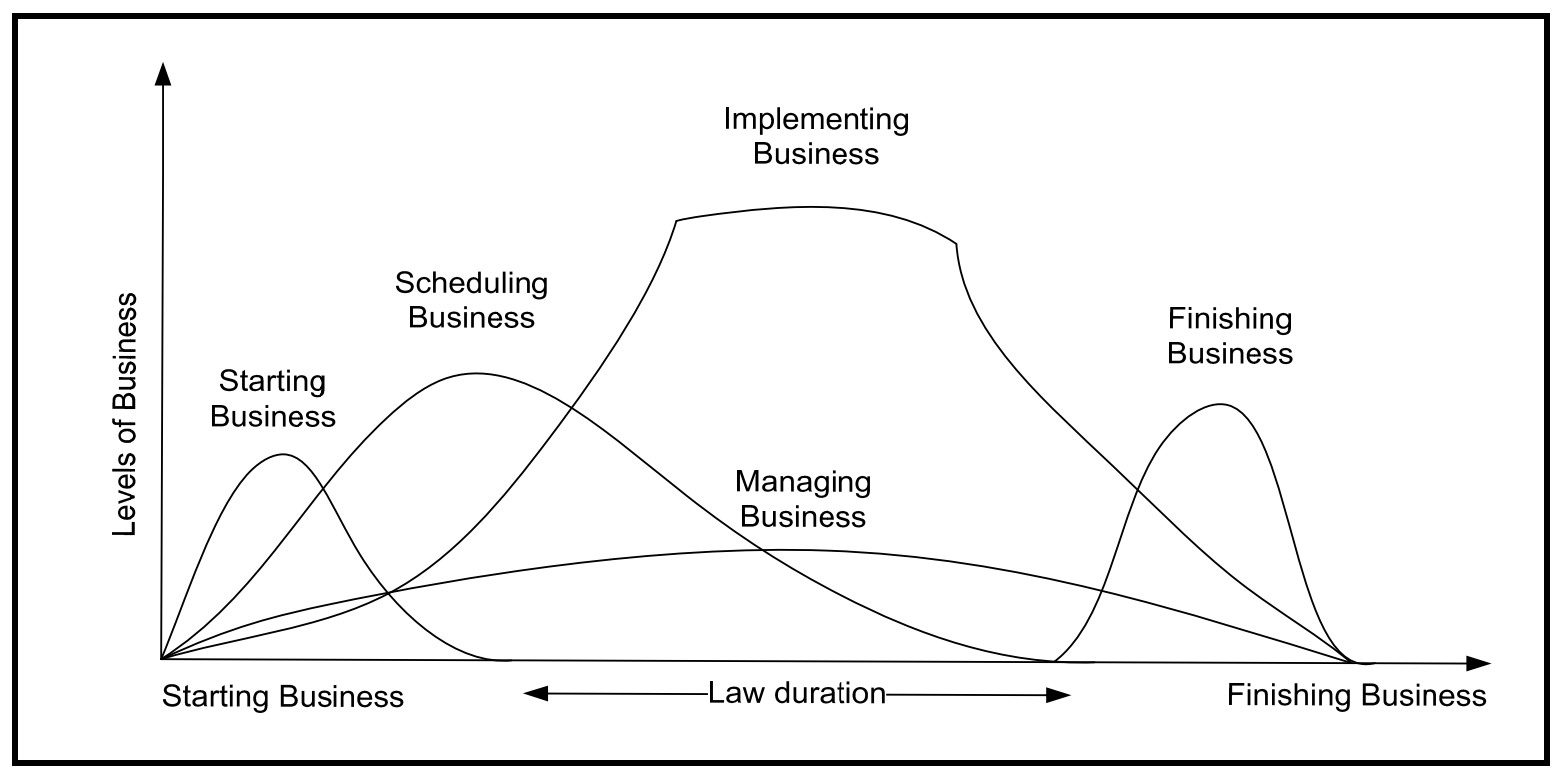

Figure 1 . The life cycle of e-business

\section{Methodology and Discussion}

The proposed model entertains the buyer and sellers entries. Both the concerns of buyer and sellers are illustrated in Figure 2 (a \& b).

2(a)

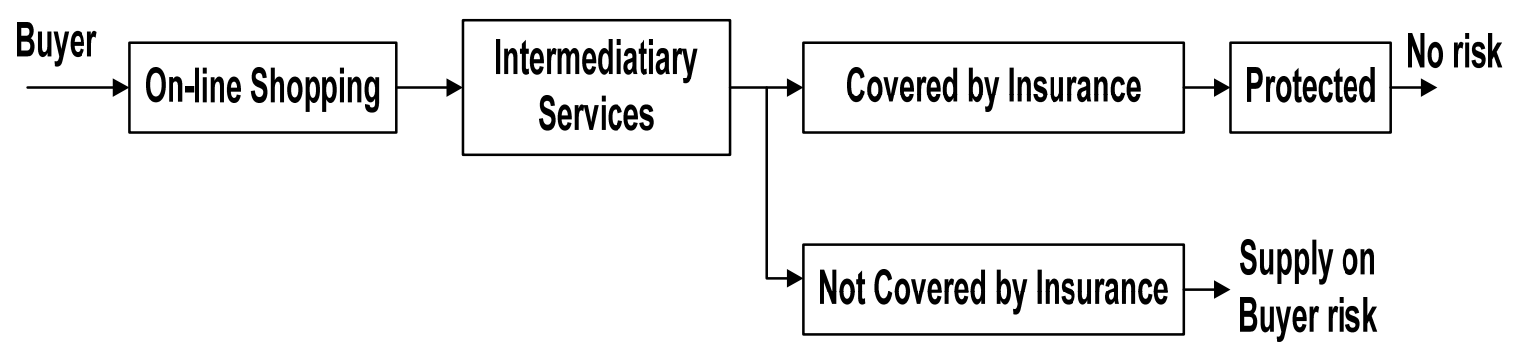

$2(b)$

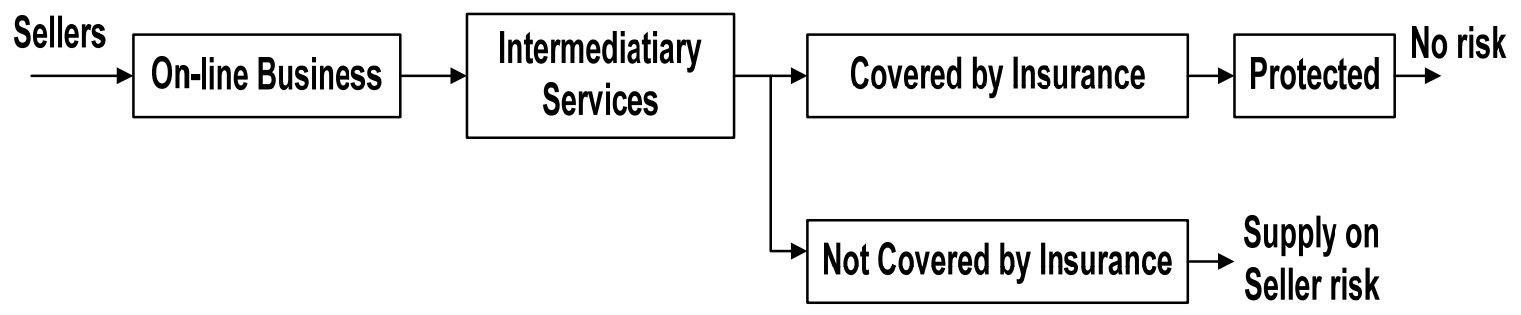

Figure 2. Proposed models for; a) Buyer protection b) Seller protection 
Figures 2(a) provides protection to the buyer, the intermediary provides protection. Figures 2(b) provides protection to the seller, the intermediary provides protection. Both, consumers and vendors decide to include the services of intermediary then the possibility of safety increases, but in return they will pay some extra amount.

\subsection{Discussion on Figure 2}

The consumer's main concerns are quality and shipment (speedy delivery) within the allowed time. The vendor's main concern is in-time payment. Quality is considered the specification to which a set of inherent characteristics fulfills the requirements. From the definition of quality it is apparent that if the product received does not match the consumer's expectations, then a predicament will emerge. Similarly, payments in-time provides confidence to the seller and they can involve more assists in the business and the circle will increase.

\section{E-law Model}

Different types of laws exist related to different crimes in every country. The implementation of law against crime indicates that the ritz of the law exists in that country. Therefore the e-laws must be bringing in practice for e-business to provide guaranteed transaction.

\subsection{Discussion on Figure 3}

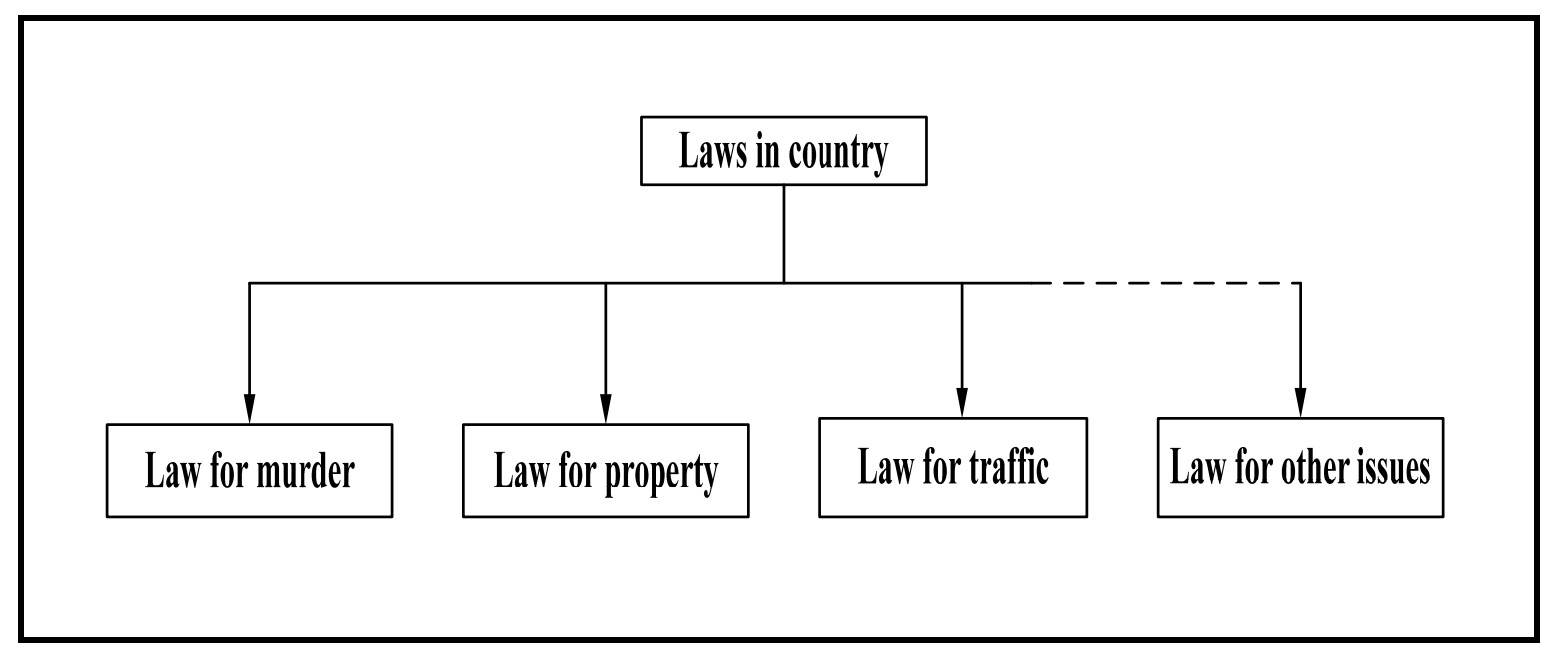

Figure 3. Different types of laws in practice

Legislature aims to highlight and implement regulation that would find suitable ground between consumers and vendors. The implementation of law against crime must come in use to reduce the crime rate. So crime is related directly to progress, if crime rate is low then the progress rate will be high. Therefore the e-laws must be practice for e-business. E-laws only point with crimes related to frauds, such as payments and quality of product as shown in Figure 4.

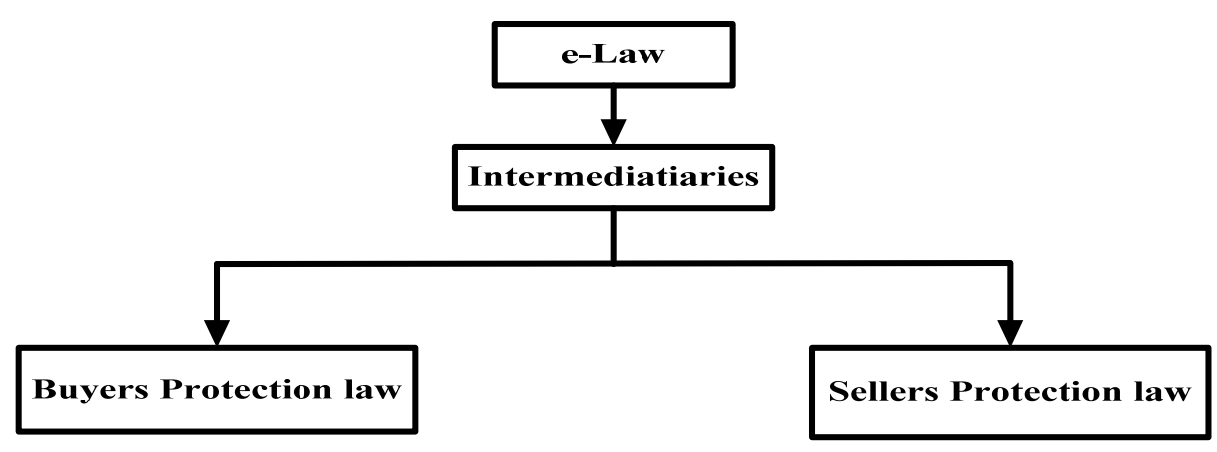

Figure 4. E-law practice between buyers and sellers 


\subsection{Discussion on Figure 4}

Consumers always demand for good quality of product and vendors are interested in imbursements leading to the challenge always arises between consumers and vendors based on imbursement and attribute. The concept of hybrid law combines between two groups/parties. The proposed e-law implementation in an on-line deal is shown in Figure 5.

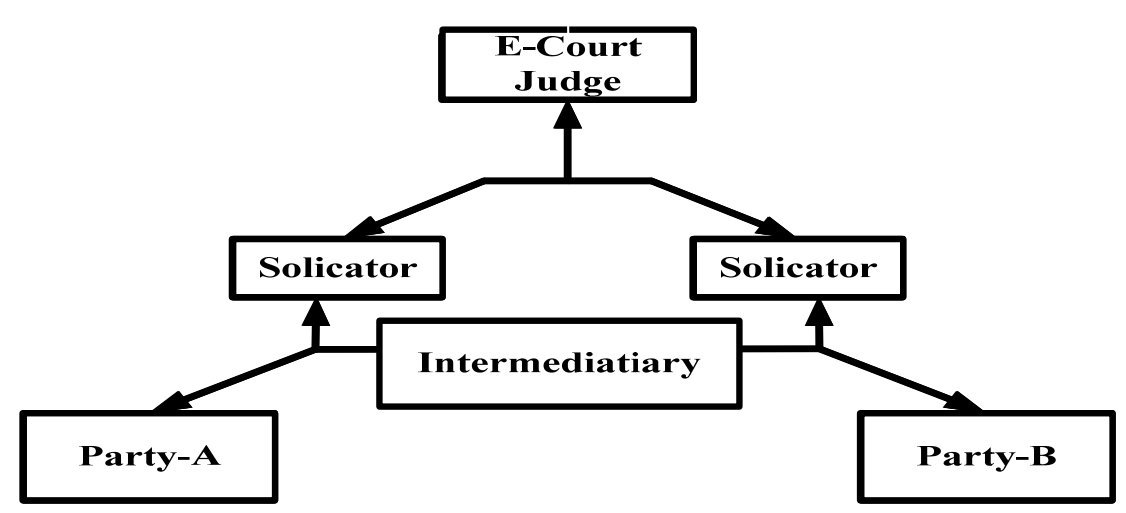

Figure 5. The intermediary involvement in transaction

The intermediary will provide protection through the solicitor to both parties, which may be considered in any scenario, such as, $B 2 B, B 2 C, B 2 B 2 C$ or $C 2 C$.

\subsection{Discussion on Figure 5}

The buyer's contribution is to pay for quality; is the cost of conformance plus the cost of nonconformance. Conformance means delivering products that meets requirements and fitness for use. In case of nonconformance, which focus on the responsibilities for failure or not meeting quality expectations? In case if quality does not meet as decided at the time of purchase then the glitch will emerge, and this constitutes legal litigation through the solicitor and finally to the judge for his judgments.

On the side of vendor imbursements are his interests and if it is not paid accordingly then tribulation will arise. Payments are based on different types; first, fixed price or lump sum; this involves a fixed total price for a well-defined product or service. Secondly, cost reimbursable; involves payment to the seller for direct and indirect costs. Thirdly, time and material contracts; the hybrid of both fixed price and cost reimbursable is used. Fourthly, unit price contracts; require the buyer to pay the seller a predetermined amount per unit of service.

The concern of intermediary is clear to make the situation for deal smooth and the interest of both buyer and seller must be protected. In case of any raw arises then the role of intermediary must become active to facilitate both sides' solicitors.

\section{Conclusions}

The process of thinking and rethinking is continued in human lives to result in progress, which is needed for better quality. Both buyers and sellers wanted to have safe transactions on-line. As someone says very correctly that human select his living on the same grounds as his fore fathers, why it is like this, that is because they feel least resistance due to rich experience. Legal participation on-line is important for safe transaction. Deals must be made based on technology such as skype face to face and must be recorded for evidence. The presence of three parties' buyers, sellers and intermediary is inevitable for both payments transaction and product quality. Therefore, both consumer and vendor must understand each other's concern, and a proper system to decide upon to eliminate irregularities if occurs and must resolve them amicably.

\section{Acknowledgement}

I am grateful to the Research Centre (RC), College of Computer and Information Sciences (CCIS), for extending me all continuous support and assistance during this research work. I am thankful to all those who contributed in any form to make this research successful. 


\section{References}

Chun-lin, W. (2011). How to Regulate Computer Crime in Germany Criminal Law. The 6th ICCSE, 384-385.

Eiselen, S. (2011). The Requirements for the Inclusion of Standard Terms in International Sales Contracts. Potchefstroom Electronic Law Journal, 14(1). Retrieved from http://hdl.handle.net/10394/4494

E-law Business Law Update: The Law society of Manitoba. (2011). Statutory Publications.

Laudon, K., \& Traver, C. (2011). E-Commerce. Pearson.

Laurie, B., \& Bohm, N. (2003). An Interface between Law and Technology, 1-13.

Mahmoud, C. B., \& Nigel, R. (2011). Independent Commission of Inquiry.

McNamara, C. (2012). Basic Guide to E-Commerce (Doing Business Over the Internet/Web). Retrieved from http://managementhelp.org/computers/e-commerce.htm

Moira, P. (2011). E-commerce Law: An Australian \& United States, Free Trade Agreement Opportunities \& Challenges.

Salzman, L., \& Sookman, B. (2011). Electronic Commerce Protection Regulations. Retrieved from http://www.barrysookman.com/2011/09/20/electronic-commerce-protection-regulations

The Electronic Commerce and Information, Consumer Protection Amendment and Manitoba Evidence Amendment ACT. (2012). Manitoba Laws. Statutory Publications. Retrieved from http://web2.gov.mb.ca/laws/index.php

United Nation. (1999). UNCITRAL. Model Law on EC with guide to enactment. UNITED NATIONS Publication, New York.

White, R., \& Haines, F. (2005). Crime and Criminology: An Introduction to Criminal Law (2nd ed.). Oxford: OUP. 